\title{
Carbon Nanosheets Synthesis in a Gliding Arc Reactor: On the Reaction Routes and Process Parameters
}

\author{
Xintong $\mathrm{Ma}^{1} \cdot$ Sirui $\mathrm{Li}^{1} \cdot$ Rohit Chaudhary $^{1} \cdot$ Volker Hessel $^{2} \cdot$ Fausto Gallucci $^{1}$
}

Received: 16 April 2020 / Accepted: 10 August 2020 / Published online: 27 August 2020

(C) The Author(s) 2020

\begin{abstract}
Non-thermal plasma is a promising technology for high purity nanomaterial synthesis in a fast, flexible and controllable process. Gliding arc discharge, as one of the most efficient non-thermal plasmas, has been widely used in gas treatment but rarely studied for the nanomaterial synthesis. In this study, a comparison study for carbon nanosheets synthesis including toluene dissociation and graphite exfoliation was investigated in a 2D gliding arc reactor at atmospheric pressure. The effects of gas flow rate, precursor concentration and power input on the structures of carbon nanosheets produced through the two synthesis routes were explored and compared. Amorphous carbon nanosheets were produced in both approaches with a few crystalline structures formation in the case of toluene dissociation. The thickness of carbon nanosheets synthesized from graphite exfoliation was less than $3 \mathrm{~nm}$, which was thinner and more uniform than that from toluene dissociation. The flow rate of carrier gas has direct influence on the morphology of carbon nanomaterials in the case of toluene dissociation. Carbon spheres were also produced along with nanosheets when the flow rate decreased from 2 to $0.5 \mathrm{~L} / \mathrm{min}$. However, in the case of graphite exfoliation, only carbon nanosheets were observed regardless of the change in flow rate of the carrier gas. The generated chemical species and plasma gas temperatures were measured and estimated for the mechanism study, respectively.
\end{abstract}

Keywords Gliding arc discharge · Carbon nanosheets synthesis · Toluene dissociation · Graphite exfoliation · Non-thermal plasma

Electronic supplementary material The online version of this article (https://doi.org/10.1007/s1109 0-020-10120-z) contains supplementary material, which is available to authorized users.

Sirui Li

S.Li1@tue.nl

1 Inorganic Membranes and Membrane Reactors, Sustainable Process Engineering, Department of Chemical Engineering and Chemistry, Eindhoven University of Technology, De Rondom 70, 5612 AP Eindhoven, The Netherlands

2 School of Chemical Engineering, University of Adelaide, Adelaide 5005, Australia 


\section{Introduction}

Carbon nanosheets (CNSs) with thickness in the nanoscale have ultrahigh surface-to-volume ratio [1], which can provide a stable and active surface for energy storage and conversion in many applications such as the lithium-ion batteries [2], hydrogen storage materials [3] and catalyst supports [4]. The synthesis of CNSs is mainly carried out through conventional methods including chemical vapor deposition [5], hydrothermal synthesis [6] and chemical/mechanical exfoliation [7,8]. Somani et al. [5] synthesized CNSs with 20-35 layers by evaporating and pyrolyzing camphor in the furnace $\left(700-850{ }^{\circ} \mathrm{C}\right)$ with argon. Fang et al. [6] adopted hydrothermal method to produce CNSs by heating phenol and formaldehyde in an oven at $130{ }^{\circ} \mathrm{C}$ for $20 \mathrm{~h}$. The CNSs with $4 \mathrm{~nm}$ thickness were obtained after drying and calcining the samples at $400-500{ }^{\circ} \mathrm{C}$ for $2 \mathrm{~h}$. Song et al. [7] utilized chemical exfoliation to synthesize CNSs with $2-5 \mathrm{~nm}$ thickness by sonicating graphite in alcohol solution for $20 \mathrm{~h}$ and oxidative acid solution for $72 \mathrm{~h}$. Overall, the CNSs synthesized by above methods generally require long reaction time and high temperature. Thus, non-thermal plasma technology is proposed as an alternative approach for the synthesis of CNS.

The research of non-thermal plasma has received increasing attentions in different areas such as $\mathrm{CO}_{2}$ conversion [9, 10], nitrogen fixation [11, 12], VOC decomposition [13, 14] and bio-medical applications $[15,16]$. The reactive species such as energetic electrons, radicals and ions provide the possibility to achieve the high conversion of reactants at atmospheric pressure and relatively low temperatures. It also promotes temperature-sensitive applications since the temperature of heavy particles is significantly lower than electrons temperature in non-thermal plasma. In the recent years, this technology is also widely used in the synthesis of different nanomaterials including metal materials [17-19] and carbon nanomaterials [20-22]. The products with high purity and good quality can be achieved when the plasma parameters are well-controlled [23]. For the synthesis of CNSs, plasmaenhanced chemical vapor deposition (PCVD) is one of the common methods, which decomposes carbon source vapor in the substrate via the combination of plasma treatment and heating effect for CNSs production. For example, CNSs with thickness of $2 \mathrm{~nm}$ were synthesized by Wang et al. [21] via microwave discharge reaction at $1200-3000{ }^{\circ} \mathrm{C}$.

Gliding arc discharge is one of the non-thermal plasmas, which is also defined as warm plasma since the characteristics of gliding arc are intermediate between cold plasma and thermal plasma [24]. Gliding arc discharge presents some advantages over other plasma types such as atmospheric operation, high flexibility and productivity. Most of reported researches on gliding arc discharge focus on gas conversion and decontamination treatments covering $\mathrm{CO}_{2}$ conversion [25], methane conversion [26] and VOC emission control [14]. The research on carbon nanomaterial synthesis was rarely studied in a gliding arc reactor, although there are a few papers that reported the formation of carbon nanomaterial [26-28], most of them aimed at achieving high conversion of reactants like $\mathrm{CH}_{4}$ with the carbon deposition as by-products. Hu et al. [26] converted methane to $\mathrm{C}_{2}$ hydrocarbons and hydrogen, resulting in a few carbon deposits in the electrode. Sperka et al. [27] explored the effect of hyper gravity on the morphology of carbon nanomaterials by decomposing $\mathrm{CH}_{4}$ in a gliding arc reactor. Methane was converted into hydrogen and graphene sheets researched by Wu et al. [28] in a rotating gliding arc reactor. So far, the synthesis of carbon nanomaterials by gliding arc plasma reactors has not been fully studied. Questions such as suitable carbon sources and synthesis routes remain to be explored which are the topic of our research of carbon nanomaterials synthesis in a $2 \mathrm{D}$ gliding arc plasma reactor. 
In this study, the synthesis of CNSs was explored in a gliding arc reactor via two routes, chemical vapor dissociation and graphite exfoliation. All of reactions were carried out at atmospheric pressure and Ar was used as carrier gas for plasma generation. Toluene was chosen as the carbon source for chemical vapor dissociation. Since toluene belongs to harmful substances (VOCs), the conversion of it would also contribute to environment protection. For graphite exfoliation, electrode made from graphite was used directly as carbon source. The produced CNSs from two routes were collected for characterization analysis. The effect of gas flow rate, precursor concentration and power input on the morphology of carbon nanosheets in two routes were also explored and compared in detail.

\section{Experimental Section}

\section{Experimental Setup}

The experiments were carried out in a 2D gliding arc discharge reactor as shown in Fig. 1. The reactor consists of two knife-shape stainless steel/graphite electrodes with thickness of $1 \mathrm{~mm}$ and height of $63 \mathrm{~mm}$ covered by quartz plate. The width of each electrode is $20 \mathrm{~mm}$ with $2 \mathrm{~mm}$ narrowest gap for arc generation. The reaction volume of the reactor is $1.01 \mathrm{~cm}^{3}$ in total. One of the electrodes is connected to a high voltage output and the other one is grounded via an external resistor $(10 \Omega)$ for current measurement. The gliding arc discharge reactor is supplied by an AC high voltage-power supply (AFS generator G15S-150 K) operating in a burst mode with a power of $8 \mathrm{~W}$ and a frequency of $50 \mathrm{kHz}$. For the burst mode operation, the time of voltage applied and voltage switched off were kept constant at $10 \mathrm{~ms}$ and $1 \mathrm{~ms}$, respectively. The applied voltage $\left(\mathrm{V}_{1}\right)$ was measured by a high voltage probe, while the voltage $\left(\mathrm{V}_{2}\right)$ on the external resistor was recorded by another voltage probe. All the electrical signals including voltage and current were measured by a four-channel digital oscilloscope. The current, discharge power and the specific energy input (SEI) were calculated as in Equations (1), (2).
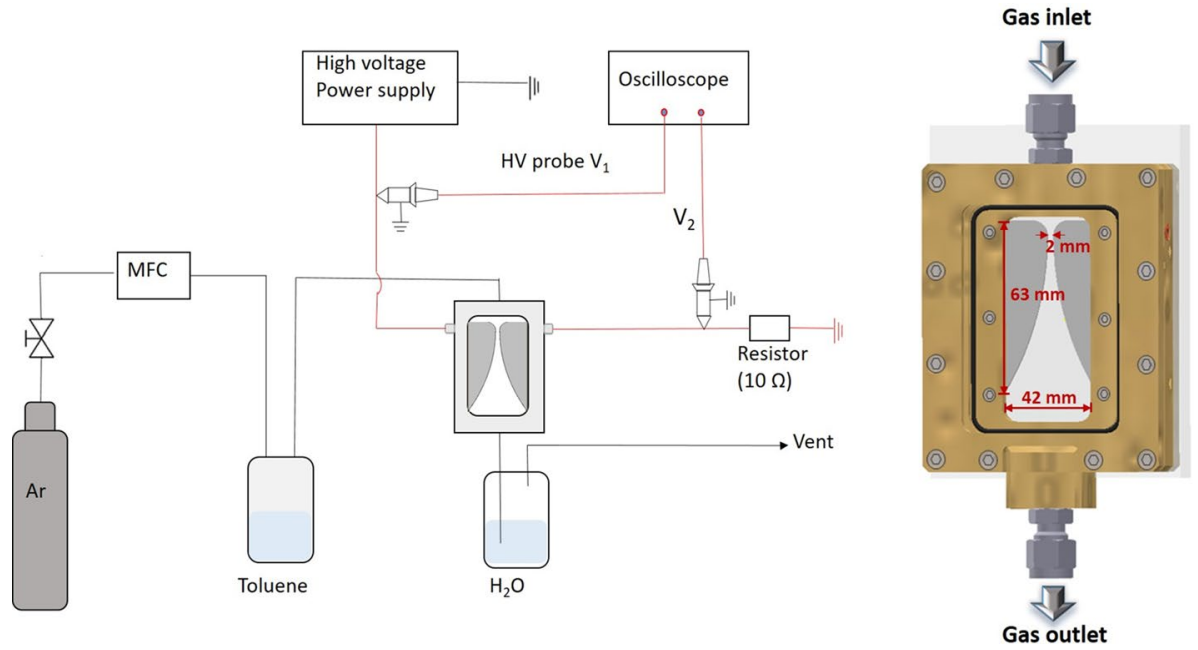

Fig. 1 Schematic diagram of the experimental setup (left) and reactor (right) 


$$
\begin{gathered}
\mathrm{P}(W)=\frac{1}{\mathrm{~T}} \int_{0}^{\mathrm{T}} \mathrm{VIdt} \\
\mathrm{SEI}\left(\mathrm{J} \mathrm{L}^{-1}\right)=\frac{\text { Discharge power }(\mathrm{W})}{\text { Flow rate }(\mathrm{L} \mathrm{min}-1)} \cdot 60\left(\mathrm{~s} \mathrm{~min}^{-1}\right)
\end{gathered}
$$

In this work, Ar was used as the carrier gas for plasma generation in a flow rate range of $0.5-2 \mathrm{~L} / \mathrm{min}$. In the case of toluene dissociation, 3-min gliding arc plasma was used to treat evaporated toluene vapor carried by Ar with a flow rate of $0.5 \mathrm{~L} / \mathrm{min}, 1 \mathrm{~L} / \mathrm{min}, 1.5 \mathrm{~L} / \mathrm{min}$ and $2 \mathrm{~L} / \mathrm{min}$ at $20{ }^{\circ} \mathrm{C}$. The effect of toluene concentration on the CNSs structure was also explored by accelerating the toluene evaporation via heating the container to $40{ }^{\circ} \mathrm{C}$ and $60{ }^{\circ} \mathrm{C}$. Most of the produced nanomaterials were collected from the deposition on quartz wall for analysis. However, minor amount of them, which is hardly quantifiable, was blew into a water container. In the case of graphite exfoliation, graphite electrode (AC-K500, GF Machining Solutions Pte.Ltd.) was used as carbon source for exfoliation in the gliding arc reactor for an hour at $20{ }^{\circ} \mathrm{C}$. After plasma treatment, most of produced CNSs were collected inside the water container followed by drying in the oven at $60{ }^{\circ} \mathrm{C}$ for analysis. There was also a small part of the product, less than $20 \%$ of total product, deposited on the quartz wall. For the analysis, the obtained CNSs powder from two routes was used for Raman and X-ray diffraction analysis directly. The powder dispersed in water was applied for further characterizations such as Transmission electron microscopy (TEM) and Atomic force microscope (AFM).

\section{Characterization and Measurements}

Labram confocal Raman microscope (WITec) was used to characterize the structure of CNSs by using a $532 \mathrm{~nm}$ laser as the excitation source. The morphology of carbon nanomaterials was observed by Transmission electron microscopy via a FEI Tecnai 20 (Sphera) microscopy operated with a $200 \mathrm{kV} \mathrm{LaB}_{6}$ filament. The chemical compositions of the produced CNSs were identified by using an X-ray photoelectron spectroscopy (XPS) from Thermo Scientific K-Alpha with an aluminum anode (Al K $\alpha=1486.6 \mathrm{eV}$ ) for recording spectra. X-ray diffraction patterns of the synthesized CNSs were obtained with a Rigaku Miniflex Powder Diffractometer using $\mathrm{Cu}-\mathrm{K} \alpha 1$ radiation with a wavelength of $1.54056 \AA$. The scans were recorded with a speed of $0.2^{\circ} / \mathrm{min}$ from $10^{\circ}$ to $90^{\circ}$. The height of CNSs was measured by tipping-mode AFM and analysed with nanoscope software (V6.14r1). The optical emission spectrum (OES) was recorded by using an HR2000 + ES spectrometer (Ocean Optics, Inc.) with an optical fiber placed outside the reactor to collect the light emission.

\section{Results and Discussion}

\section{Carbon Nanomaterial Synthesis from Toluene Dissociation}

Toluene vapor was carried by Ar gas with the flow rate tested from 0.5 to $2 \mathrm{~L} / \mathrm{min}$ in the reactor. The concentration of toluene changed in a small range between 1.2 and $1.7 \%$ with 
Table 1 Summary results from the reaction at the various flow rates

\begin{tabular}{llllll}
\hline $\begin{array}{l}\text { Ar flow rate }(\mathrm{L} / \\
\mathrm{min})\end{array}$ & $\begin{array}{l}\text { Toluene concen- } \\
\text { tration }(\%)\end{array}$ & Power $(\mathrm{W})$ & SEI (kJ/L) & $\begin{array}{l}\text { Residence } \\
\text { time }(\mathrm{s})\end{array}$ & $\begin{array}{l}\text { Single gliding } \\
\text { arc cycle }(\mathrm{ms})\end{array}$ \\
\hline 0.5 & 1.7 & 7.6 & 0.91 & 0.12 & 10.0 \\
1.0 & 1.6 & 7.5 & 0.45 & 0.06 & 5.7 \\
1.5 & 1.4 & 7.6 & 0.30 & 0.04 & 4.2 \\
2.0 & 1.2 & 7.4 & 0.22 & 0.03 & 3.4 \\
\hline
\end{tabular}

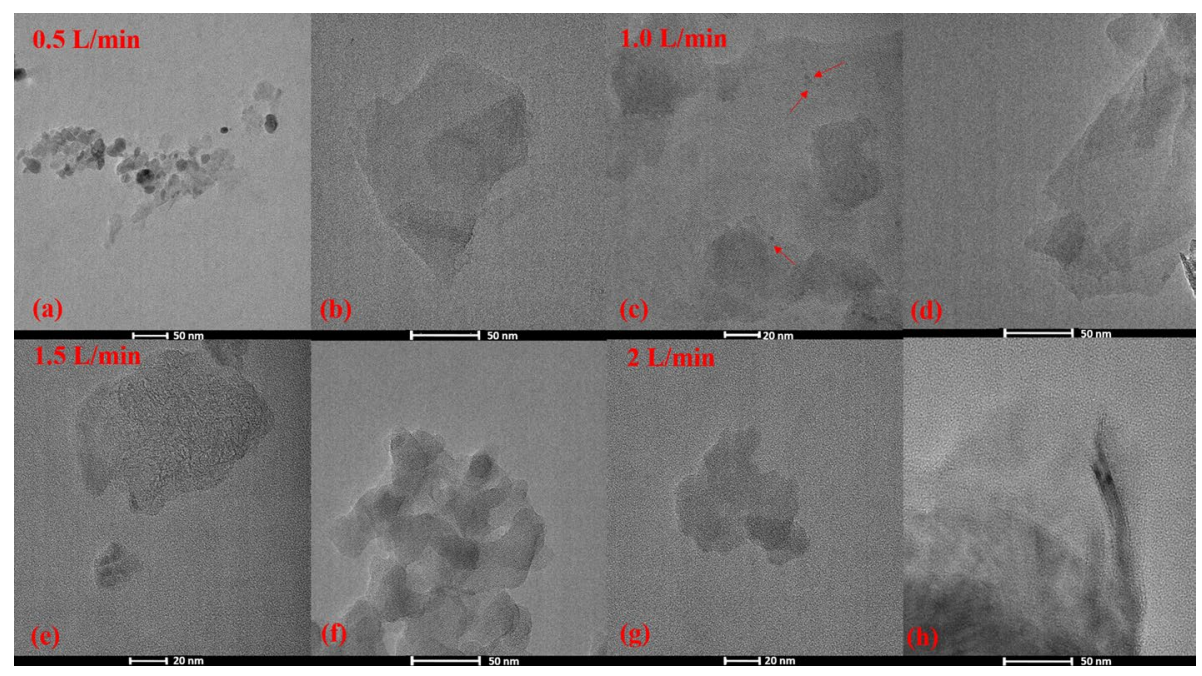

Fig. 2 TEM images of produced carbon nanomaterials with Ar flow rate $0.5 \mathrm{~L} / \mathrm{min}(\mathbf{a}, \mathbf{b}), 1 \mathrm{~L} / \mathrm{min}(\mathbf{c}$, d), $1.5 \mathrm{~L} / \mathrm{min}(\mathbf{e}, \mathbf{f})$ and $2 \mathrm{~L} / \mathrm{min}(\mathbf{g}, \mathbf{h})$. Red arrows mark the position of particles formation (Color figure online)

the Ar flow rate. The toluene concentration, power consumption and SEI were measured and calculated (as presented in Table 1). The height of arc in all cases was around $3.0 \mathrm{~cm}$ as shown in Fig. S1. There is no significant change in the power consumption, while the SEI and the residence time of reactant decrease with the increase of total flow rates. The typical voltage and current waveforms of gliding arc at different flow rates were present in Fig. S2. Single gliding arc cycle can be observed from the voltage and current waveforms, which decreases from 10 to $3.4 \mathrm{~ms}$ with the increasing flow rate. The reactant vapor undergoes longer residence time and the larger SEI at lower flow rate, which may lead to the structure difference of carbon nanomaterials. The characterization of material synthesized is shown in following section.

Figure 2 shows the TEM images of the produced carbon nanomaterials at different Ar flow rates. As shown in Fig. 2a, b, both of carbon spheres and carbon nanosheets were observed in the product from experiment at the flow rate of $0.5 \mathrm{~L} / \mathrm{min}$. However, only a few carbon spheres with red arrows were observed on the carbon layer at $1 \mathrm{~L} / \mathrm{min}$ (Fig. 2c). In the case of 1.5-2 L/min, multilayer CNSs were observed instead of carbon spheres (Fig. 2e-h). Overall, most of the carbon nanomaterials were layer-structured while carbon spheres were also found in the case of low flow rate. The main reason for this phenomenon could be the difference of energy and residence time for the different gas flow rates. 
In the case of $0.5 \mathrm{~L} / \mathrm{min}$, both of the SEI and residence time are the highest. As reported [21], graphitization at high temperature induce the coalescence of graphene sheets and the formation of loop at the tip of sheets, resulting in the formation of graphene nanoparticles. Thus, the high SEI and long residence time could lead to the formation of loops and carbon nanoparticles at low flow rate. In addition, more carbon nanomaterials deposit on the quartz wall at low flow rate especially in the position of arc generation due to low velocity (Fig. S3). The deposition mass on quartz plate was $1.9 \mathrm{mg}$ at $0.5 \mathrm{~L} / \mathrm{min}$ and $0.5 \mathrm{mg}$ at $2 \mathrm{~L} / \mathrm{min}$, respectively. The heating effect of gliding arc with long residence time could promote the formation of loops in the deposited carbon nanomaterials. Moreover, in order to observe the detailed structures, the HR-TEM images from $2 \mathrm{~L} / \mathrm{min}$ are also provided in Fig. S4. Most of products show amorphous structures as shown in Fig. S4a, while lattice fringes can also be found in some parts in the image as Fig. S4b. According to the XRD pattern in Fig. S5a, the produced CNSs are amorphous structures without intensive carbon peaks. Overall, it can be concluded that the majority of CNSs from toluene dissociation are amorphous with a few amorphous-to-crystalline structures transition. Raman spectra were presented for further study of the structures in next step.

The Raman spectra of the carbon nanomaterial from different flow rates are shown in Fig. 3, all spectra exhibited typical carbon feature peaks at $1360 \mathrm{~cm}^{-1}, 1596 \mathrm{~cm}^{-1}$, $2697 \mathrm{~cm}^{-1}, 2935 \mathrm{~cm}^{-1}$ and $3211 \mathrm{~cm}^{-1}$. The peak positions of D band and $\mathrm{G}$ band are close to amorphous carbon as our previous report [20]. D band appeared at $1360 \mathrm{~cm}^{-1}$ demonstrates from the vibrations of carbon atoms in the disordered structures, edges or glassy carbon, which could result from the amorphous structure of carbon (Fig. S5). While the $\mathrm{G}$ band at $1596 \mathrm{~cm}^{-1}$ is related to the vibration of $\mathrm{sp}^{2}$-bonded carbon atoms in a two-dimensional hexagonal lattice [29]. In all the spectra as shown in Fig. 3, the
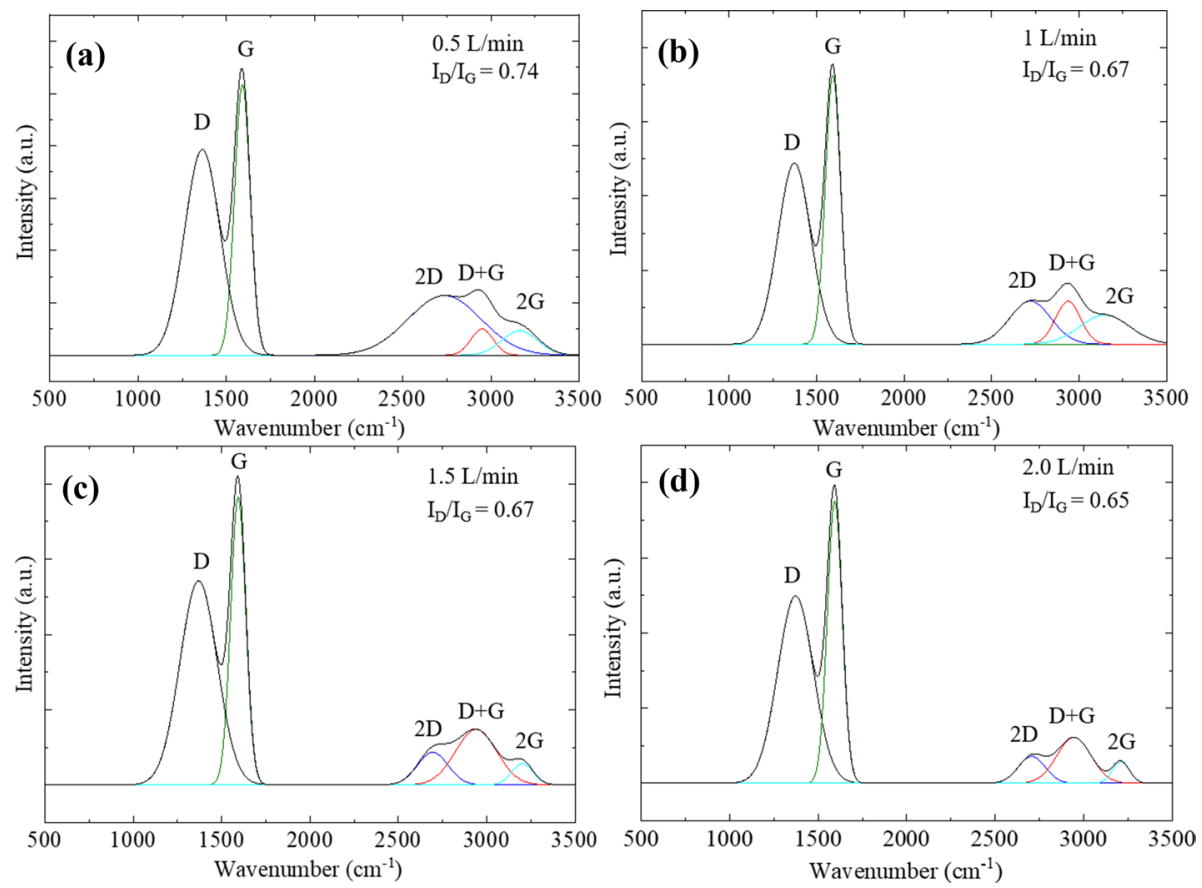

Fig. 3 Raman spectra of carbon nanomaterials produced at different flow rates 
intensity of $\mathrm{G}$ peak is higher than $\mathrm{D}$ peak, indicating there are principally $s p^{2}$ carbons with some $s p^{3}$ hybrid carbons defects. In addition, the ratio of $\mathrm{I}_{\mathrm{D}} / \mathrm{I}_{\mathrm{G}}$ decreases with the increase of Ar flow rate, indicating that the ordered $s p^{2}$ carbon structures rise with the increasing flow rate. The full width at half maximum (FWHM) of G peak declines with the increasing flow rate, implying the rise of the $s p^{2}$ carbon structures. This coincides with the result in Fig. 2. The morphology of carbon nanomaterials changes from carbon spheres/CNSs to only CNSs. In addition, $2 \mathrm{D}, 2 \mathrm{G}$ and combination bands $(\mathrm{D}+\mathrm{G})$ are also observed in the spectra.

The XPS spectra of the samples synthesized at various flow rates were reported to compare the variation of the surface functional groups. The produced CNSs were comprised with carbon $(89.1 \%)$ and oxygen element (10.9\%) from full spectrum at $2 \mathrm{~L} / \mathrm{min}$ as an example in Fig. S6a. The $\mathrm{C} 1 s$ spectra consist of four contributions at $284.5 \mathrm{eV}$, $285.4 \mathrm{eV}, 286.3 \mathrm{eV}$ and $288.8 \mathrm{eV}$ in Fig. 4, which are assigned to $\mathrm{C}-\mathrm{C}\left(s p^{2}\right), \mathrm{C}-\mathrm{C}\left(s p^{3}\right)$, $\mathrm{C}-\mathrm{O}$ and $\mathrm{C}=\mathrm{O}$ groups. These groups coincide with the groups of $\mathrm{C} 1 s$ spectra in report $[30,31]$. The concentration of carbon, including $s p^{2}$ and $s p^{3}$ structures, decreases from 80.2 to $74.5 \%$ with the increase of Ar flow rates, which could result from the variety of SEI and residence time. At low flow rate, higher SEI and longer residence time could lead to the higher carbonization degree. The oxygen spectrum consists of $\mathrm{C}-\mathrm{O}$ and $\mathrm{C}=\mathrm{O}$ groups shown in Fig. S7, which is in agreement with the analysis of carbon spectrum in Fig. 4. The $\mathrm{C}-\mathrm{O}$ and $\mathrm{C}=\mathrm{O}$ could be resulted from the physical absorption of $\mathrm{O}_{2} / \mathrm{H}_{2} \mathrm{O}$ in the toluene or oxidation in the air after the reaction.
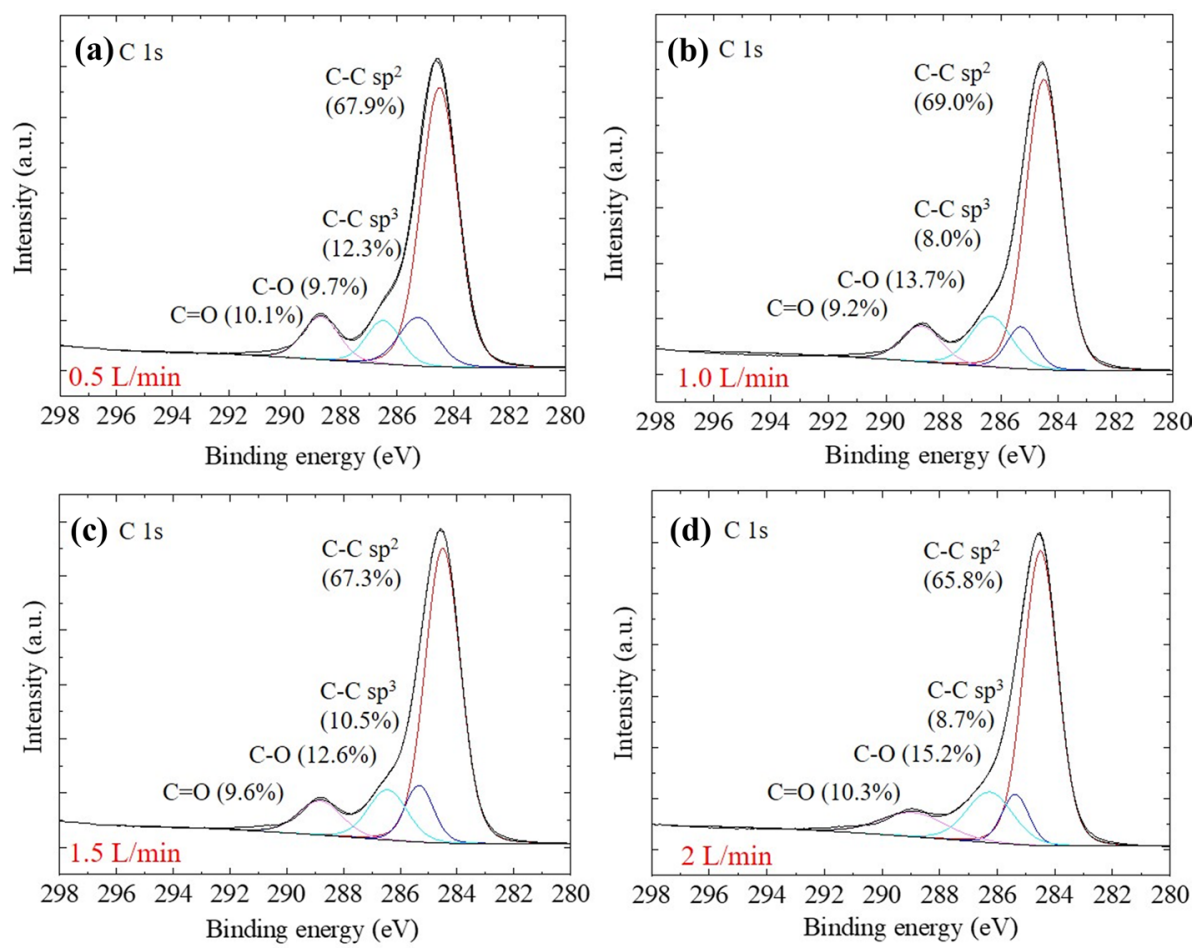

Fig. $4 \mathrm{C} 1 s$ spectra of produced carbon nanomaterials at different Ar flow rates 
In our research, toluene concentration varies in a small range from 1.2 to $1.7 \%$ within the studied flow rates. By considering the effect of concentration on the structures of CNSs, another group of tests were done with diverse toluene concentrations. The flow rate of $\mathrm{Ar}$ was fixed at $2 \mathrm{~L} / \mathrm{min}$ for the new tests. The toluene container was heated to $40{ }^{\circ} \mathrm{C}$ and $60{ }^{\circ} \mathrm{C}$ and the concentration of toluene was $2.8 \%$ and $5.5 \%$, respectively. The carbon nanomaterials synthesized at $20-60{ }^{\circ} \mathrm{C}$ were collected after plasma treatment and analysed by Raman spectroscopy. Results were shown in Fig. S8. The $\mathrm{I}_{\mathrm{D}} / \mathrm{I}_{\mathrm{G}}$ and $\mathrm{I}_{2 \mathrm{D}} / \mathrm{I}_{\mathrm{G}}$ were calculated for all spectra. However, there is no obvious change observed, $\mathrm{I}_{\mathrm{D}} / \mathrm{I}_{\mathrm{G}}$ is in a range of $0.65-0.67$ and $\mathrm{I}_{2 \mathrm{D}} / \mathrm{I}_{\mathrm{G}}$ is between $0.12-0.13$. The variation of $\mathrm{I}_{\mathrm{D}} / \mathrm{I}_{\mathrm{G}}$ is within $3 \%$ so that the tiny changes can be negligible. All the experiments were repeated at least three times. Therefore, it can be concluded that the concentration of toluene in a range of $1.2-5.5 \%$ has no evident effect on the structure of carbon nanomaterial synthesis. This is different with the case reported by $\mathrm{Wu}$ [28], in which $\mathrm{CH}_{4}$ was used as carbon source and the concentration of $\mathrm{CH}_{4}$ varied in a larger range of $16.7-44.4 \%$. The ratio of $\mathrm{I}_{\mathrm{D}} / \mathrm{I}_{\mathrm{G}}$ increased with the rising of $\mathrm{CH}_{4}$ concentration in their study. Therefore, in our study with toluene concentration varying within a smaller range, the main contributors to the difference of structure in our flow rate study are the SEI and residence time.

\section{Carbon Nanomaterial Synthesis from Graphite Exfoliation}

In the study of graphite exfoliation, two graphite electrodes in the gliding arc reactor were used as carbon source. Only Ar gas was injected to the reactor with a set of flow rates from 0.5 to $2 \mathrm{~L} / \mathrm{min}$. The power consumption and SEI were measured and calculated in Table 2. Unlike toluene dissociation, the height of arc increased from 3.4 to $5.5 \mathrm{~cm}$ in Fig. $\mathrm{S} 9$ and power consumption (2.0-4.0 W) show an increase tendency with the Ar flow rate. The voltage and current waveforms at different flow rates were shown in Fig. S10. The waveform from $2 \mathrm{~L} / \mathrm{min}$ was discussed as an example. The gliding arc ignited at $\sim 4.5 \mathrm{kV}$ with a high current peak at $\sim 17 \mathrm{~A}$. Then it decreased to $\sim 0.6 \mathrm{kV}$ and increased the value with arc propagation. The current waveform demonstrates an evident decreasing trend after the position of breakdown. There is only one gliding arc cycle within $10 \mathrm{~ms}$ burst time in all cases.

Figure 5 presents the morphology of synthesized carbon nanomaterials from graphite exfoliation at the flow rate from 0.5 to $2 \mathrm{~L} / \mathrm{min}$. All the materials were typical multilayer structure CNSs and most of them owned the sizes less than $100 \mathrm{~nm}$. Interestingly, the crumple structures of graphene marked with red arrows were also found including dense wrinkles in some cases (Fig. 5d). These structures present the potential of the carbon nanomaterials in energy related research such as energy storage and supercapacitors due to the high conductive property and high surface area [32]. In order to observe the

Table 2 Summary results from the reaction at the various flow rates

\begin{tabular}{lllll}
\hline $\begin{array}{l}\text { Ar flow } \\
\text { rate }(\mathrm{L} / \\
\text { min) }\end{array}$ & Arc height $(\mathrm{cm})$ & Power (W) & SEI (kJ/L) & $\begin{array}{l}\text { Residence } \\
\text { time }(\mathrm{s})\end{array}$ \\
\hline 0.5 & 3.4 & 2.0 & 0.24 & 0.12 \\
1.0 & 4.0 & 3.0 & 0.18 & 0.06 \\
1.5 & 5.0 & 3.4 & 0.14 & 0.04 \\
2.0 & 5.5 & 4.0 & 0.12 & 0.03 \\
\hline
\end{tabular}




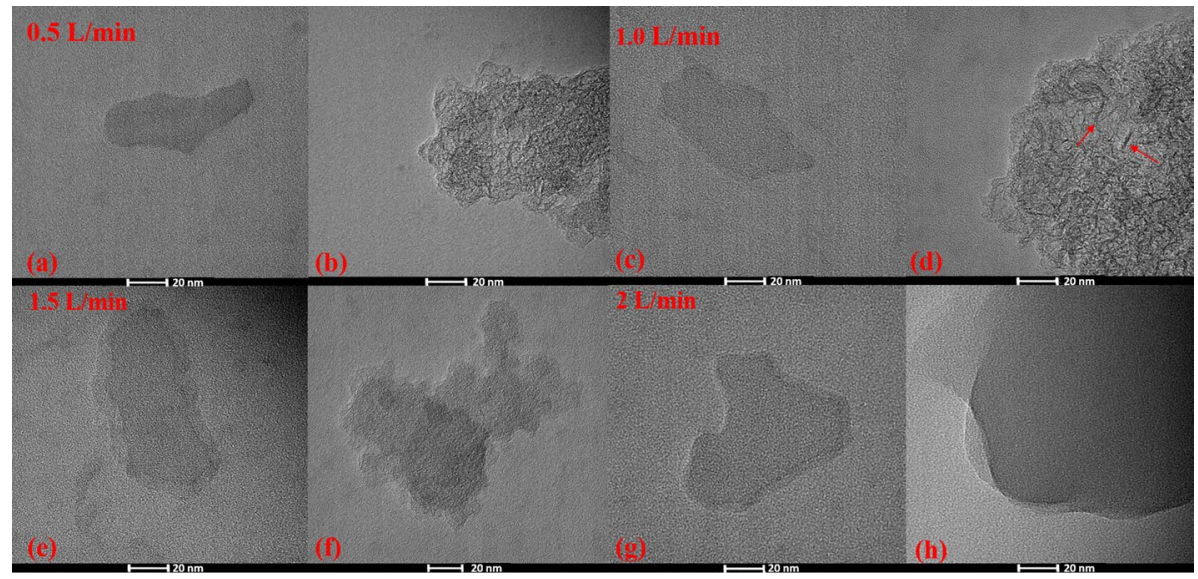

Fig. 5 TEM images of produced carbon nanomaterials with Ar flow rate $0.5 \mathrm{~L} / \mathrm{min}(\mathbf{a}, \mathbf{b}), 1 \mathrm{~L} / \mathrm{min}(\mathbf{c}, \mathbf{d})$, $1.5 \mathrm{~L} / \mathrm{min}(\mathbf{e}, \mathbf{f})$ and $2 \mathrm{~L} / \mathrm{min}(\mathbf{g}, \mathbf{h})$. Red arrows mark the position of crumples (Color figure online)

layers in detail, HR-TEM images of produced CNSs from $2 \mathrm{~L} / \mathrm{min}$ are also provided in Fig. S4c-d. From the images, the fabricated CNSs are amorphous structures with dense wrinkles, which coincides with results from XRD pattern in Fig. S5b. The layer number is less than 5 for most of cases in the observed images.

The structure of produced CNSs was further examined with Raman spectroscopy and XPS in Fig. 6. The flow rate in research range has no evident effect on the structure of CNSs, since the Raman spectra from various flow rates have no difference in Fig. 6a. The sample at flow rate of $2 \mathrm{~L} / \mathrm{min}$ as an example was further analysed for detailed structure study. The typical D band, G band and 2D band of carbon peaks were present at position of $1339 \mathrm{~cm}^{-1}, 1583 \mathrm{~cm}^{-1}$ and $2680 \mathrm{~cm}^{-1}$ in Fig. 6a, which coincide with the spectrum of nano-graphene as reported [33]. The Raman spectrum of the initial graphite electrode is also presented in Fig. 6a. The spectrum of graphite electrode demonstrates an intense $\mathrm{G}$ band and a very weak $\mathrm{D}$ band as the typical graphite structures. Compared with initial graphite electrode, the ratio of $\mathrm{I}_{\mathrm{D}} / \mathrm{I}_{\mathrm{G}}$ of product after plasma reaction is much higher (1.30), indicating the existence of high intensity of disordered structure in the structure.
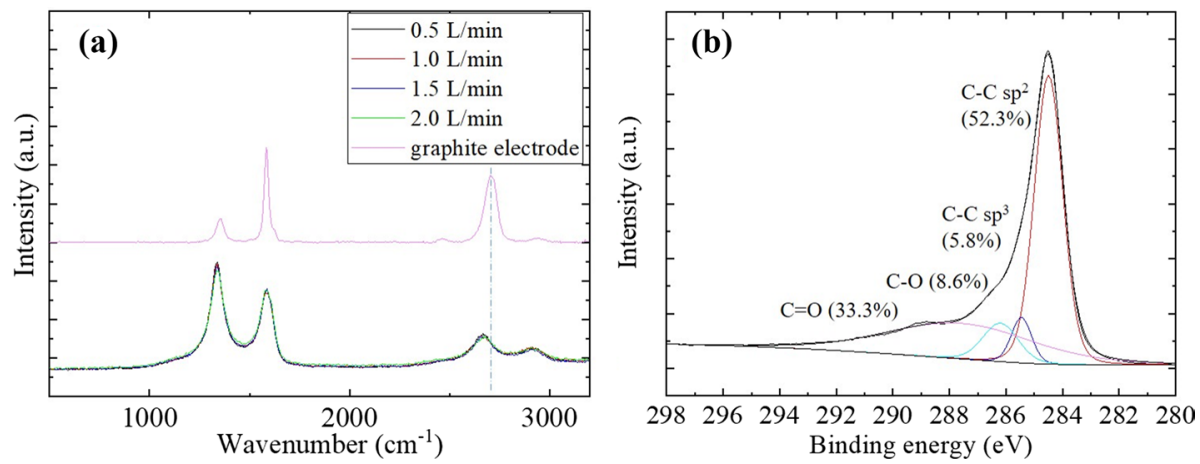

Fig. 6 Raman spectra (a) and C1s spectrum (b) of produced CNSs from graphite exfoliation 
From the TEM analysis, most of produced CNSs own the small sizes less than $100 \mathrm{~nm}$. Thus, the high intensity of D band can originate from an abundance of edges in the CNSs or amorphous structure [34]. In addition, the position of 2D band shifts from $2709 \mathrm{~cm}^{-1}$ of graphite electrode to $2680 \mathrm{~cm}^{-1}$ after reaction, implying that the layer number of CNSs decreases after plasma exfoliation process. This result is in agreement with the opinion from other study [35]. Further, for a single layer graphene, the ratio of $\mathrm{I}_{2 \mathrm{D}} / \mathrm{I}_{\mathrm{G}}$ is higher than 1 [33]. In this study, the ratio of $\mathrm{I}_{2 \mathrm{D}} / \mathrm{I}_{\mathrm{G}}$ is 0.40 , indicating the synthesis of multi-layer structure CNSs. The composition of CNSs was discussed by XPS analysis. The produced CNSs consists of carbon (90.6\%) and oxygen element (9.4\%) from full spectrum at $2 \mathrm{~L} / \mathrm{min}$ as an example in Fig. S6b. In carbon spectrum of Fig. 6b, the bond of graphitic carbon, hybrid $s p^{3}$ carbon, $\mathrm{C}-\mathrm{O}$ and $\mathrm{C}=\mathrm{O}$ groups were shown at the binding energy of $284.5 \mathrm{eV}, 285.4 \mathrm{eV}$, $286.2 \mathrm{eV}$ and $287.6 \mathrm{eV}$. Hybrid $s p^{3}$ carbon can derive from the amorphous structure of $\mathrm{CNSs}$ in Fig. S5. The oxygen spectrum, containing $\mathrm{C}-\mathrm{O}, \mathrm{C}=\mathrm{O}$ and absorbed water/oxygen, could originate from the oxidation during drying process in Fig. S11.

In addition, the productivity of CNSs was discussed based on the mass of products. In Fig. 7, the CNSs deposited on the quartz wall at flow rate of $0.5 \mathrm{~L} / \mathrm{min}$ were obviously more than those at flow rate of $2 \mathrm{~L} / \mathrm{min}$. The mass of collected powder from water container was also higher $(0.8 \mathrm{mg})$ at $0.5 \mathrm{~L} / \mathrm{min}$ than that $(0.4 \mathrm{mg})$ at $2 \mathrm{~L} / \mathrm{min}$. The reason
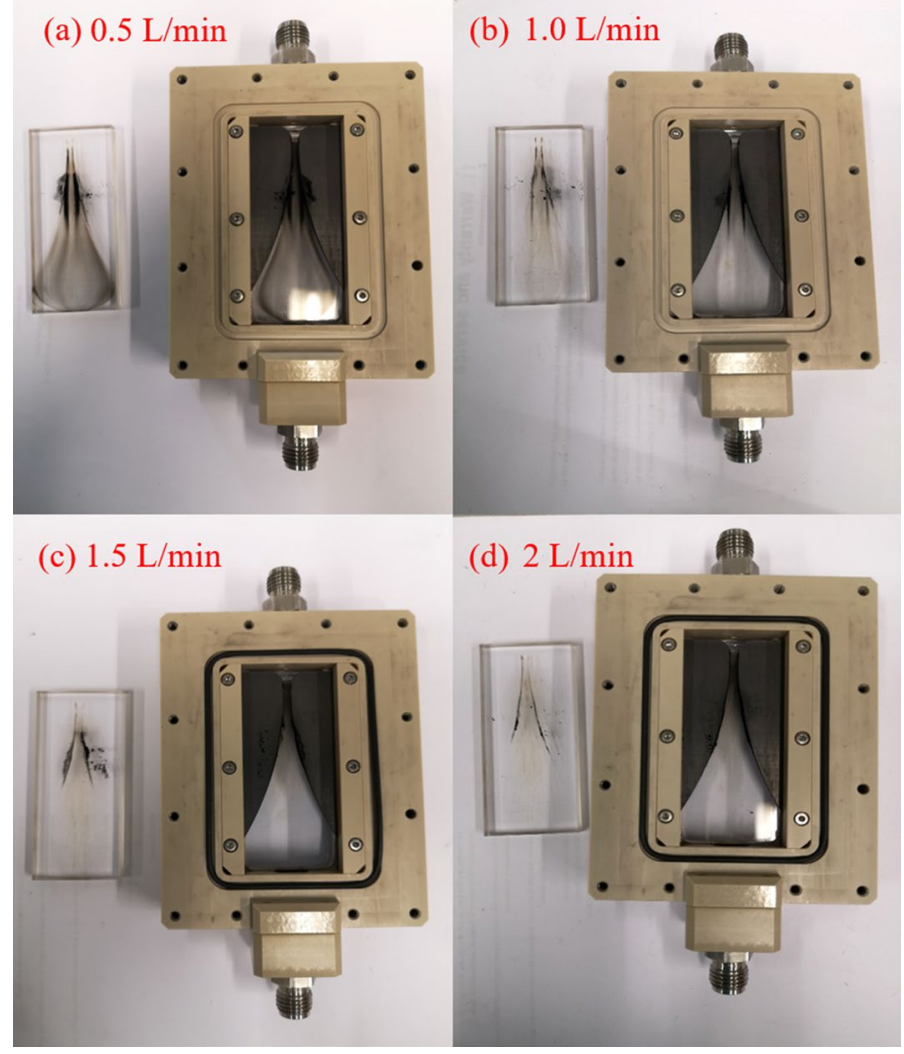

Fig. 7 The deposition of CNSs from graphite exfoliation at different flow rates 
could be explained as follows. Higher SEI and longer residence time at low flow rate give rise to the production of more energetic electrons, Ar species and related higher heating temperature. These factors work on the graphite electrode surface directly, resulting in a higher productivity at low flow rate.

Apart from the gas flow rate, the effect of power input on the carbon nanomaterials was also explored. The flow rate was fixed at $2 \mathrm{~L} / \mathrm{min}$ for both of cases with the variation of power input in a range of 4-16 W. For toluene dissociation, the ratio of $\mathrm{I}_{\mathrm{D}} / \mathrm{I}_{\mathrm{G}}$ increases from 0.63 to 0.73 (Fig. S12) with SEI from 0.12 to $0.33 \mathrm{~kJ} / \mathrm{L}$ (Table S1), indicating that the $s p^{3}$ hybrid carbons defects and edges rise with the increase of SEI. This coincides with the results in the flow rate study. Higher SEI leads to more $s p^{3}$ carbons and edges production. The mass of product also increases from 0.1 to $1.4 \mathrm{mg}$ with SEI. For graphite exfoliation, there is no obvious change in the Raman spectra with the increasing SEI in a range of $0.08-0.20 \mathrm{~kJ} / \mathrm{L}$ (Table $\mathrm{S} 1$ ). The ratios of $\mathrm{I}_{\mathrm{D}} / \mathrm{I}_{\mathrm{G}}$ and $\mathrm{I}_{2 \mathrm{D}} / \mathrm{I}_{\mathrm{G}}$ are within a teeny-variation range, 1.25-1.27 and 0.35-0.38, respectively (Fig. S13). The mass of product rises from 0.1 to $1.0 \mathrm{mg}$ with an increase of SEI. In sum, the rise of power input is indexed to higher SEI of the plasma reaction, resulting in the slight change of products in toluene dissociation and no obvious change in graphite exfoliation within research range. In addition, higher SEI also incurs higher productivity in both of approaches. The results are in agreement with the conclusions from the flow rate study, which also varies SEI by the adjustment of flow rate.

\section{The Layer Number and Synthesis Mechanism Comparison}

The dominating synthesized carbon nanomaterials were multi-layer structure CNSs based on the Raman analysis in Figs. 3 and 6. Thus, the number of nanosheets layer needs to be further explored in both of toluene dissociation and graphite exfoliation. In Fig. 8, the typical AFM images and height study of produced CNSs were analyzed in two cases at $2 \mathrm{~L} /$ min with a scan area of $600 \times 600 \mathrm{~nm}$ on mica substrates, respectively. In order to verify the distribution of products from both of routes, extra AFM images with various scales are presented in Fig. S14-S15. The CNSs from toluene dissociation exhibit a large irregular layer in the image with some small-size nanosheets around in Fig. 8a. The height of the large layer is approximately $0.90 \mathrm{~nm}$, presenting the existence of 2-3 layers base on the thickness of single-layer graphene $(0.335 \mathrm{~nm})$ [36]. However, some thicker and smaller CNSs also appear in the image with the thickness around $4 \mathrm{~nm}$ (11 layers) in Fig. 8b. In general, the structure of CNSs produced in toluene dissociation is not very uniform. The reason could be explained from the following aspects: In the process of CNSs production, highly energetic electrons achieve the ionization, excitation and dissociation of carbon source in the plasma vapor dissociation reaction, resulting the low-temperature growth of CNSs. On the one hand, the dissociation process of carbon source is too fast under the plasma treatment. The CNSs are synthesized in the gas phase and stack together before depositing on the quartz wall. On the other hand, the concentration of carbon source $(\sim 1 \%)$ could be not low enough in our research, the high vapor pressure can accelerate the pyrolytic decomposition in gas phase. The formed new layers deposit on the old ones, resulting in the generation of non-uniform thickness. In the case of graphite exfoliation (Fig. 8c), the distribution of the CNSs seems more uniform. The sizes of CNSs are around $50 \mathrm{~nm}$ with the thickness in a range of $0.92-1.58 \mathrm{~nm}$ (2-5 layers) in Fig. 8d.

To further explore the reasons of the product differences in two routes, the plasma gas temperatures were estimated for both of approaches. In this study, the $\mathrm{C}_{2}$ species, observed 

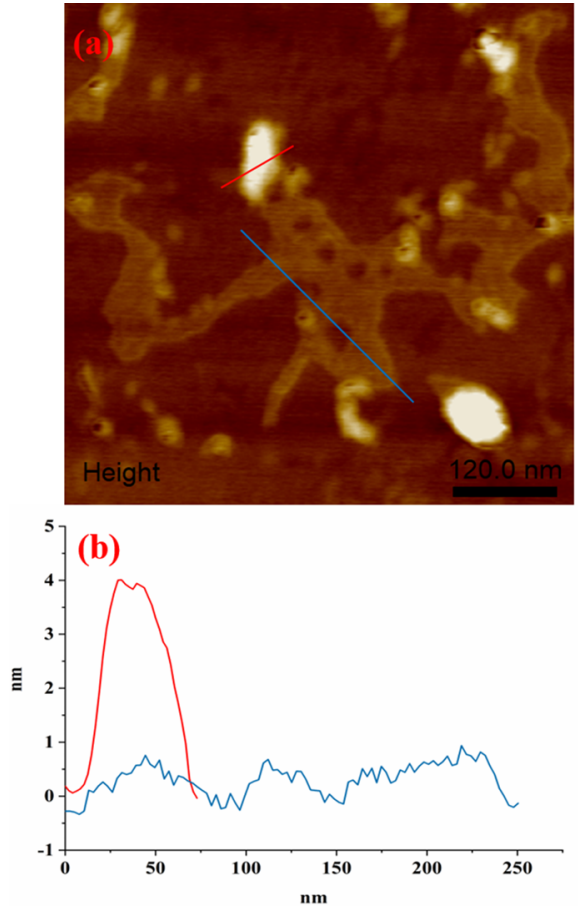
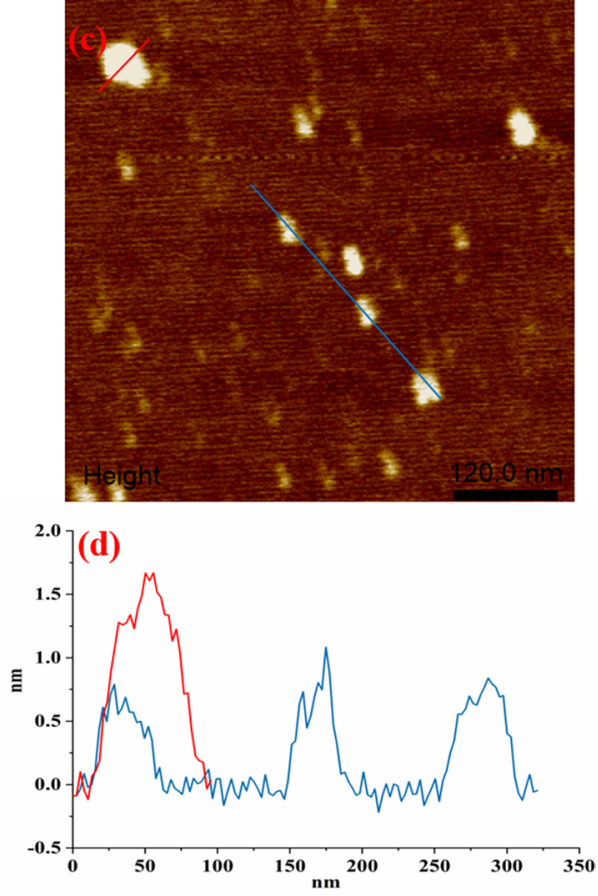

Fig. 8 AFM image and height analysis in toluene dissociation (a, b) and graphite exfoliation (c, d)

from high current arcs by optical emission spectrometer in both of cases, were applied for temperature estimation [37]. Thus, the peak at $516 \mathrm{~nm}$, corresponding to $\Delta \mathrm{v}=0$ of $\mathrm{C}_{2}$ swan bands in a range of 510-520 nm, was used for rotational temperature estimation by fitting experimental spectra in Specair. Figure 9 demonstrates the experimental spectra as well as the fitted ones. The estimated rotational temperature is around $3000 \mathrm{~K}$ and $1200 \mathrm{~K}$ in toluene dissociation and graphite exfoliation, respectively. Rotational temperature is normally
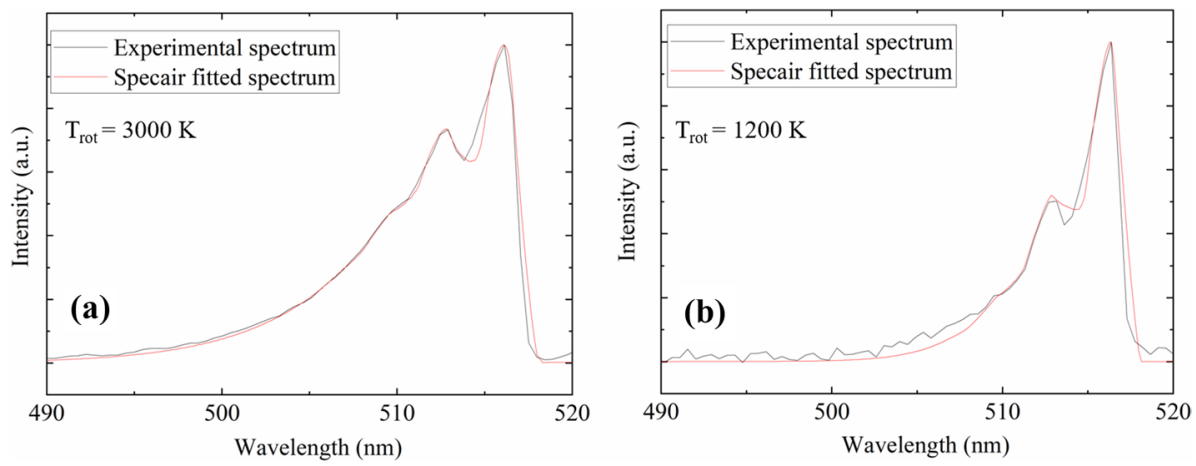

Fig. 9 Experimental spectrum and Specair fitted spectrum in toluene dissociation (a) and graphite exfoliation (b) 
regarded as an approximation of gas temperature in atmospheric-pressure plasma reaction as reported [37-39]. Therefore, the estimated temperatures represent for gas temperature in the two reactions. These numbers coincide with the reported gliding arc gas temperature in a range of 1000-4000 K [40, 41]. Further, the gas temperatures from the reactor outlet were also measured, which were lower than $310 \mathrm{~K}$ in both of cases.

As reported, the gas temperature is not uniform in the gliding arc reactor [42-44]. The gas temperature of thin plasma arc channel is much higher than the surrounding gas temperature [44]. Therefore, temperature uniformity can be one of reasons to explain the non-uniform distribution in toluene dissociation and relatively uniform distribution in graphite exfoliation. For toluene dissociation, the CNSs were fabricated in the gas phase by toluene vapor dissociation. Thus, the uniformity of gas temperature has stronger influences on the quality of products during plasma reaction. In addition, the product from toluene dissociation deposits in the various positions of quartz wall during the reaction rather than being collected from water tank as graphite exfoliation. Therefore, the product can be further affected by the heating effects from various plasma regions. As for graphite exfoliation, the CNSs were generated from graphite electrode exfoliation and the products were blown to reactor directly. Hence, the gas temperature has less effects on the product structures than that from toluene dissociation. Moreover, although the estimated gas temperatures are around $3000 \mathrm{~K}$ and $1200 \mathrm{~K}$ for two approaches. Nevertheless, the residence time in high temperature arc channel is too short to form crystal structure. The average gas temperature from outlet is lower than $310 \mathrm{~K}$. Therefore, the majority of CNSs products from toluene dissociation are amorphous with a few amorphous-to-crystalline structures transition. CNSs from graphite exfoliation are still amorphous, since the temperature for graphitic structure formation should be higher than $2000 \mathrm{~K}$ as reported [45].

Optical emission spectra were measured during the plasma reaction to observe the toluene dissociation and graphite exfoliation with the identification of the generated excited species in Fig. 10. In Fig. 10a, the dominant peaks from 460 to $620 \mathrm{~nm}$ are $C_{2}$ swan band together with $\mathrm{CH}$ modes at $431 \mathrm{~nm}$ and atomic hydrogen $\mathrm{H}_{\alpha}$ at $656 \mathrm{~nm}$ [46]. These species are resulted from the dissociation of toluene and can identify the presence of hydrocarbon species such as $\mathrm{C}_{2} \mathrm{H}_{\mathrm{x}}$ and $\mathrm{CH}_{\mathrm{y}}$, which are important for the formation of carbon nanomaterials [47, 48]. Apart from the carbon species, prominent emission peaks between 690 and $850 \mathrm{~nm}$ are related to highly
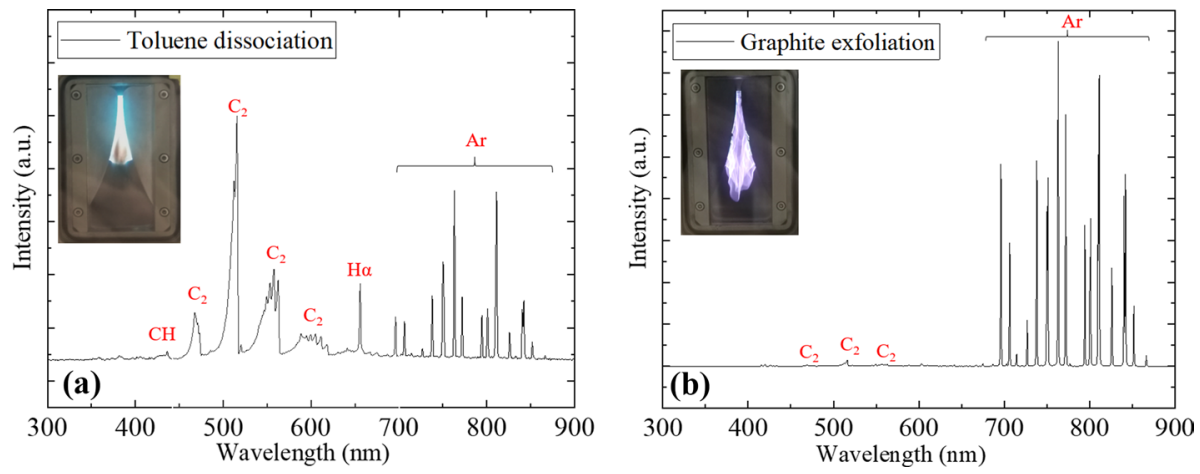

Fig. 10 The OES spectra from toluene dissociation (a) and graphite exfoliation (b) 
excited electronic states of Ar atomic transitions (Ar I), which also takes a primary role in the spectra of graphite exfoliation in Fig. 10b. However, only less intense $\mathrm{C}_{2}$ species are observed except Ar species in the spectrum of graphite exfoliation due to the difference of CNSs formation mechanism between two routes. In this study, when plasma was generated in the gliding arc reactor, a high density of electrons was produced to dissociate toluene or exfoliate graphite electrode to produce $\mathrm{C}_{2}$ species, promoting the nucleation and growth of carbon and leading to CNSs formation. The arc images from two synthesis routes were also compared in Fig. 10, which present typical blue color arc from high density carbon species in toluene dissociation and purple color arc from dominant excited Ar species in graphite exfoliation.

Toluene dissociation was explored based on the OES spectra recorded. The possible decomposition reactions were present in Eqs. (3)-(6) based on studies [49, 50]. The principle process of toluene dissociation is induced by electron impact dissociation. High energy electrons react with toluene and argon molecules via inelastic collisions to form metastable Ar species, generating phenyl, methyl and benzyl radicals [50]. Then the radicals can either combine to generate intermediate products such as bibenzyl and other aromatic hydrocarbons in Eqs. (7-9), or continue to dissociate to other radicals and products. The possible dissociation routes for benzyl radicals are presented as an example in Eqs. (10-12), since the production of benzyl radicals are more favorable due to the low reaction enthalpy $(84.4 \mathrm{kcal} / \mathrm{mol}) \mathrm{com}$ pared with phenyl [51]. Then the radicals and intermediate products further dissociate to carbon species or recombine to form various aromatic chemicals based on the reaction conditions as studied in reports [51,52], followed by carbonization process under the impact of electrons and $\mathrm{Ar}^{*}$ species or directly flowing away with carrier gas. This dissociation reaction process terminates when the partial pressure of the carbon products exceeds the saturated vapor pressure at the deposition temperature. Finally, the decomposed products deposit on the quartz wall directly or polymerize further to CNSs on the surface of quartz wall. Based on the detection results from OES, the $\mathrm{C}_{2}, \mathrm{H}, \mathrm{CH}$ species also prove that the dissociation of toluene ring takes place during the plasma reaction. The abundance of $\mathrm{C}_{2}$ in Ar-containing plasmas can be attributed to the available pathways for $\mathrm{C}_{2}$ production, resulting from the energy transfer between Ar* species with ethylene or acetylene species in Eqs. $(6,10)$. This is in correspondence with the opinions in other studies $[53,54] . \mathrm{H}_{\alpha}$ and $\mathrm{CH}$ species are possible to originate from $\mathrm{H}$ and $\mathrm{CH}_{3}$ radicals in Eqs. $(4,5,12)$ during the dissociation process. Notably, toluene dissociation is a complex process with hundreds of possible reaction routes as explored by modelling and GC-MS in many studies [51, 52]. This study aims at the comparison study of CNSs synthesis between two reaction routes. Thus, only several primary reactions from toluene dissociation are presented for the OES and mechanism study. The entire toluene dissociation routes and detailed mechanism study are out of scope in current study. As for graphite exfoliation, high temperature arcs with energetic electrons act on the graphite electrode surfaces directly. As reported [55], a critical temperature of $800 \mathrm{~K}$ should be exceeded for a quick graphite exfoliation to occur. The estimated gas temperature in the graphite exfoliation is around $1200 \mathrm{~K}$. Thus, the arcs enable to overcome the attractive van der Waals interactions between graphite layers and initiate the exfoliation of graphite, resulting in the formation of $\mathrm{C}_{2}$ species from electrode surface observed in OES. The $\mathrm{C}_{2}$ species further promotes the nucleation and growth of CNSs. Finally, CNSs products were blown away from reactor with Ar flow and collected in the water tank. 


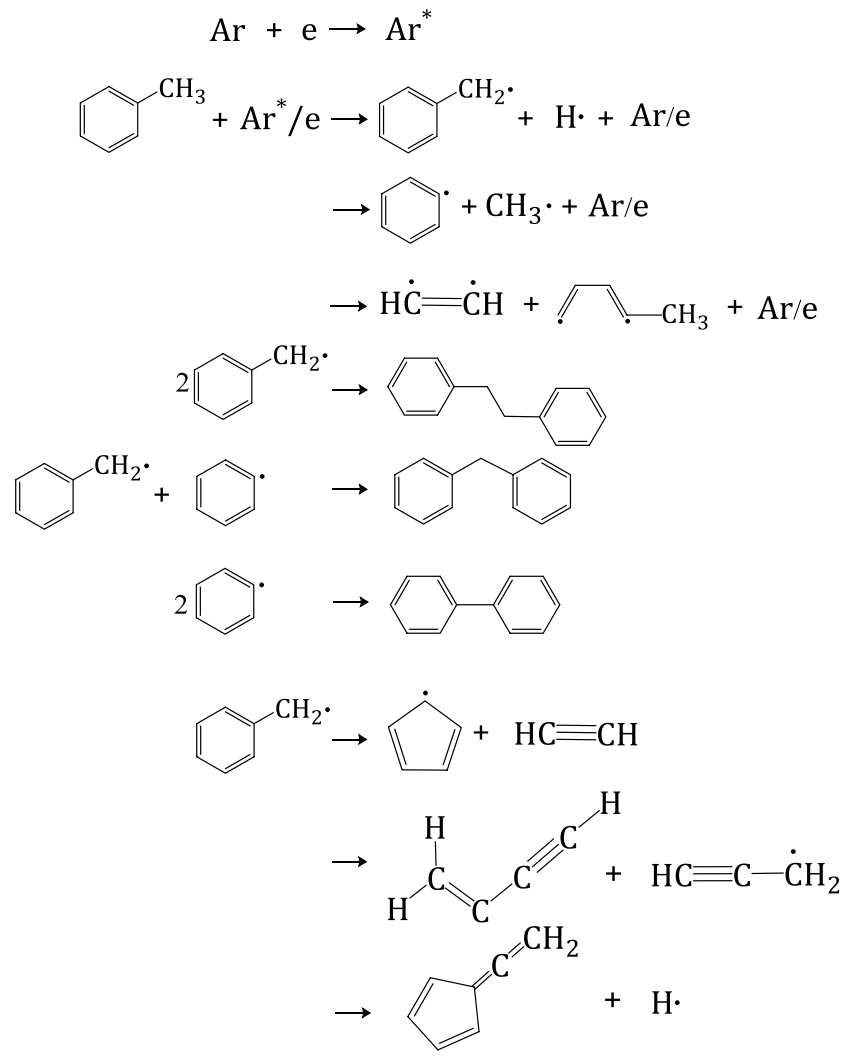

\section{Conclusion}

In this study, a comparison study for carbon nanosheets synthesis including toluene dissociation and graphite exfoliation was explored in a gliding arc reactor at atmospheric pressure. In toluene dissociation, the effect of gas flow rate, precursor concentration were explored on the morphology of carbon nanosheets. The product morphology changed from only CNSs to CNSs/spheres with the decrease of flow rate from $2 \mathrm{~L} / \mathrm{min}$ to $0.5 \mathrm{~L} /$ min of Ar, since the high SEI and residence time give rise to the formation of loops and carbon nanoparticles. Within the tested range, the toluene concentration is not relevant to the structure of CNSs. In graphite exfoliation, the structures of produced CNSs have no obvious change at all tested flow rates. However, the productivity is higher in the case of low flow rate. This tendency coincides with the results in toluene dissociation and was explained in detail. The rise of power input is indexed to higher SEI of the plasma reaction, resulting in the slight change of products in toluene dissociation and no obvious change in graphite exfoliation within research range. The results are in accordance with the conclusions from the flow rate study, which also varies SEI by the adjustment of flow rate. Further, the structures and reaction species were compared for the mechanism study between 
two routes. The produced CNSs from graphite exfoliation with 2-5 layers were thinner and more uniform than the CNSs from toluene dissociation via AFM analysis. The possible reasons were explained based on estimated plasma gas temperatures, carbon sources and reaction mechanisms in detail. In OES study, high intensity reactive species were observed in toluene dissociation including $\mathrm{C}_{2}, \mathrm{CH}$ and atomic hydrogen $\mathrm{H}_{\alpha}$ except Ar species. While only less intense $\mathrm{C}_{2}$ species were found in graphite exfoliation. Thus, the possible dissociation reactions were proposed for further mechanism analysis.

In this study, we found that the structures of nanomaterials could be flexible due to the controllable plasma operation parameters in a gliding arc reactor. However, some possible enhancements are necessary for the high quality and crystal carbon nanomaterials production, which are shown as follows. (1) An improvement of energy input may enhance the crystallization degree of carbon nanomaterials. As report [28], higher operating voltage promoted the CNSs synthesis with a high crystallization structure in a gliding arc reactor. Thus, energy input can be one of parameters related to the structure control. (2) The addition of selective catalysts can facilitate the nanomaterial formation with specific morphology. For example, nickel catalyst was proved for the generation of the carbon nanotubes in different plasma reactions $[10,56]$. Thus, the morphology of nanomaterials produced by gliding arc reactor might be well-controlled with selective catalysts. (3) A combination between gliding arc discharge technology and other technologies can improve the quality or the property during/after the plasma treatment. For example, chemical exfoliation is an effective method to decrease the thickness of CNSs. But it generally requires long reaction time to achieve the exfoliation process. The thickness of CNSs reduced from 22 to $9 \mathrm{~nm}$ after $44 \mathrm{~h}$ chemical exfoliation treatment in report [7]. If the chemical exfoliation was combined for treating CNSs after plasma treatment. It is promising to produce thin layer CNSs in a relative short time. In addition, the functional CNSs with surface groups are also possible to generate by changing carrier gas like nitrogen for N-doped CNSs production. Overall, gliding arc discharge presents the potentials in the nanomaterial synthesis with high productivity, further research will be needed in the future.

Acknowledgements The authors acknowledge the technical assistance from Carlo Buijs (TEM) from Sustainable Process Engineering Section, Tiny Verhoeven and Jiadong Zhu (XPS) from Molecular Catalysis Section of Chemical Engineering and Chemistry Department, Eindhoven University of Technology.

Funding This work was supported by the Chinese Scholarship Council (CSC).

\section{Compliance with Ethical Standards}

Conflict of interest The authors declare that they have no conflict of interest.

Open Access This article is licensed under a Creative Commons Attribution 4.0 International License, which permits use, sharing, adaptation, distribution and reproduction in any medium or format, as long as you give appropriate credit to the original author(s) and the source, provide a link to the Creative Commons licence, and indicate if changes were made. The images or other third party material in this article are included in the article's Creative Commons licence, unless indicated otherwise in a credit line to the material. If material is not included in the article's Creative Commons licence and your intended use is not permitted by statutory regulation or exceeds the permitted use, you will need to obtain permission directly from the copyright holder. To view a copy of this licence, visit http://creativecommons.org/licenses/by/4.0/. 


\section{References}

1. Fan H, Shen W (2015) Carbon nanosheets: synthesis and application. Chemsuschem 8:2004-2027. https://doi.org/10.1002/cssc.201500141

2. Liu J, Liu XW (2012) Two-dimensional nanoarchitectures for lithium storage. Adv Mater 24:40974111. https://doi.org/10.1002/adma.201104993

3. Liu G, Wang Y, Jiao L, Yuan H (2014) Understanding the role of few-layer graphene nanosheets in enhancing the hydrogen sorption kinetics of magnesium hydride. ACS Appl Mater Interfaces 6:1103811046. https://doi.org/10.1021/am502755s

4. Yu L, Ruan H, Zheng Y, Li D (2013) A facile solvothermal method to produce ZnS quantum dotsdecorated graphene nanosheets with superior photoactivity. Nanotechnology 24:375601. https://doi. org/10.1088/0957-4484/24/37/375601

5. Somani PR, Somani SP, Umeno M (2006) Planer nano-graphenes from camphor by CVD. Chem Phys Lett 430:56-59. https://doi.org/10.1016/J.CPLETT.2006.06.081

6. Fang Y, Lv Y, Che R et al (2013) Two-dimensional mesoporous carbon nanosheets and their derived graphene nanosheets: synthesis and efficient lithium ion storage. J Am Chem Soc 135:1524-1530. https://doi.org/10.1021/ja310849c

7. Song WL, Cao MS, Lu MM et al (2013) Improved dielectric properties and highly efficient and broadened bandwidth electromagnetic attenuation of thickness-decreased carbon nanosheet/wax composites. J Mater Chem C 1:1846-1854. https://doi.org/10.1039/c2tc00494a

8. Zhang X, Xie X, Wang H et al (2012) Enhanced photoresponsive ultrathin graphitic-phase C3N4 nanosheets for bioimaging. J Am Chem Soc 135:18-21. https://doi.org/10.1021/ja308249k

9. Snoeckx R, Bogaerts A (2017) Plasma technology: a novel solution for $\mathrm{CO}_{2}$ conversion? Chem Soc Rev 46:5805-5863. https://doi.org/10.1039/c6cs00066e

10. Ma X, Li S, Ronda-Lloret $\mathrm{M}$ et al (2019) Plasma assisted catalytic conversion of $\mathrm{CO}_{2}$ and $\mathrm{H}_{2} \mathrm{O}$ over $\mathrm{Ni} / \mathrm{Al}_{2} \mathrm{O}_{3}$ in a DBD reactor. Plasma Chem Plasma Process 39:109-124. https://doi.org/10.1007/s1109 0-018-9931-1

11. Li S, Medrano Jimenez J, Hessel V, Gallucci F (2018) Recent progress of plasma-assisted nitrogen fixation research: a review. Processes 6:248. https://doi.org/10.3390/pr6120248

12. Cherkasov N, Ibhadon AO, Fitzpatrick P (2015) A review of the existing and alternative methods for greener nitrogen fixation. Chem Eng Process Process Intensif 90:24-33. https://doi.org/10.1016/J. CEP.2015.02.004

13. Van Den Broucke AM, Morent R, De Geyter N, Leys C (2012) Decomposition of toluene with plasmacatalysis: a review. J Adv Oxid Technol 15:232-241. https://doi.org/10.1515/jaots-2012-0201

14. Du CM, Yan JH, Cheron B (2007) Decomposition of toluene in a gliding arc discharge plasma reactor. Plasma Sour Sci Technol 16:791-797. https://doi.org/10.1088/0963-0252/16/4/014

15. Gupta TT, Ayan H (2019) Application of non-thermal plasma on biofilm: a review. Appl Sci 9:3548. https://doi.org/10.3390/app9173548

16. Nakajima N, Ito Y, Yokoyama K et al (2005) The expresssion of Mdm2 on Helicobacter pylori infected intestinal metaplasia and gastric cancer. J Clin Biochem Nutr 128:A401-A402. https://doi.org/10.3164/ jcbn.16

17. Lin L, Ma X, Li S et al (2019) Plasma-electrochemical synthesis of europium doped cerium oxide nanoparticles. Front Chem Sci Eng 13:501-510. https://doi.org/10.1007/s11705-019-1810-7

18. Ananth A, Mok Y (2016) Dielectric barrier discharge (DBD) plasma assisted synthesis of $\operatorname{Ag}_{2} \mathrm{O}$ nanomaterials and $\mathrm{Ag}_{2} \mathrm{O} / \mathrm{RuO}_{2}$ nanocomposites. Nanomaterials 6:42. https://doi.org/10.3390/nano6030042

19. Zhang X, Zhang L, Li Y, Di L (2015) Atmospheric-pressure cold plasma for fabrication of anataserutile mixed $\mathrm{TiO}_{2}$ with the assistance of ionic liquid. Catal Today 256:215-220. https://doi. org/10.1016/j.cattod.2015.04.033

20. Ma X, Li S, Hessel V et al (2019) Synthesis of luminescent carbon quantum dots by microplasma process. Chem Eng Process Process Intensif 140:29-35. https://doi.org/10.1016/j.cep.2019.04.017

21. Wang Z, Ogata H, Morimoto S et al (2014) Structure changes of MPECVD-grown carbon nanosheets under high-temperature treatment. Carbon N Y 68:360-368. https://doi.org/10.1016/j.carbo n.2013.11.012

22. Shiratori Y, Hiraoka H, Takeuchi Y et al (2003) One-step formation of aligned carbon nanotube field emitters at $400{ }^{\circ} \mathrm{C}$. Appl Phys Lett 82:2485-2487. https://doi.org/10.1063/1.1566803

23. Lin L, Wang Q (2015) Microplasma: a new generation of technology for functional nanomaterial synthesis. Plasma Chem Plasma Process 35:925-962. https://doi.org/10.1007/s11090-015-9640-y

24. Zhang $\mathrm{H}$, Li L, Li $\mathrm{X}$ et al (2018) Warm plasma activation of $\mathrm{CO}_{2}$ in a rotating gliding arc discharge reactor. J CO2 Util 27:472-479. https://doi.org/10.1016/J.JCOU.2018.08.020 
25. Indarto A, Yang DR, Choi JW et al (2007) Gliding arc plasma processing of $\mathrm{CO}_{2}$ conversion. J Hazard Mater 146:309-315. https://doi.org/10.1016/j.jhazmat.2006.12.023

26. Shuanghui H, Baowei W, Yijun L et al (2013) Conversion of methane to C2 hydrocarbons and hydrogen using a gliding Arc reactor. Plasma Sci Technol 15:555-561. https://doi. org/10.1088/1009-0630/15/6/13

27. Šperka J, Souček P, Van Loon JJWA et al (2014) Hypergravity synthesis of graphitic carbon nanomaterial in glide arc plasma. Mater Res Bull 54:61-65. https://doi.org/10.1016/j.materresbull.2014.03.013

28. Wu A, Chen H, Zheng $\mathrm{J}$ et al (2019) Conversion of coalbed methane surrogate into hydrogen and graphene sheets using rotating gliding arc plasma. Plasma Sci Technol 21:115501. https://doi. org/10.1088/2058-6272/ab21a2

29. Gu J, Zhang X, Pang A, Yang J (2016) Facile synthesis and photoluminescence characteristics of blue-emitting nitrogen- doped graphene quantum dots. Nanotechnology 27:165704. https://doi. org/10.1088/0957-4484/27/16/165704

30. Haubner K, Murawski J, Olk P et al (2010) The route to functional graphene oxide. ChemPhysChem 11:2131-2139. https://doi.org/10.1002/cphc.201000132

31. Ferreira F V, Franceschi W, Menezes BRC et al (2019) Chapter one-synthesis, characterization, and applications of carbon nanotubes. In: Yaragalla S, Mishra R, Thomas S et al (eds) Elsevier, Amsterdam, pp 1-45. https://doi.org/10.1016/b978-0-12-813248-7.00001-8

32. Deng S, Berry V (2016) Wrinkled, rippled and crumpled graphene: an overview of formation mechanism, electronic properties, and applications. Mater Today 19:197-212. https://doi.org/10.1016/J. MATTOD.2015.10.002

33. Bin WuJ, Lin ML, Cong X et al (2018) Raman spectroscopy of graphene-based materials and its applications in related devices. Chem Soc Rev 47:1822-1873. https://doi.org/10.1039/c6cs00915h

34. Kalita G, Kayastha MS, Uchida H et al (2012) Direct growth of nanographene films by surface wave plasma chemical vapor deposition and their application in photovoltaic devices. RSC Adv 2:3225-3230. https://doi.org/10.1039/c2ra01024k

35. Ferrari AC (2007) Raman spectroscopy of graphene and graphite: disorder, electron-phonon coupling, doping and nonadiabatic effects. Solid State Commun 143:47-57. https://doi.org/10.1016/j. ssc. 2007.03 .052

36. Ye S, Huang H, Yuan $\mathrm{C}$ et al (2014) Thickness-dependent strain effect on the deformation of the graphene-encapsulated Au nanoparticles. J Nanomater 2014:989672. https://doi. org/10.1155/2014/989672

37. Lin L, Starostin SA, Hessel V, Wang Q (2017) Synthesis of iron oxide nanoparticles in microplasma under atmospheric pressure. Chem Eng Sci 168:360-371. https://doi.org/10.1016/j.ces.2017.05.008

38. Laux CO, Spence TG, Kruger CH, Zare RN (2003) Optical diagnostics of atmospheric pressure air plasmas. Plasma Sour Sci Technol 12:125-138. https://doi.org/10.1088/0963-0252/12/2/301

39. Pothiraja R (2012) Plasma-chemical kinetics of film deposition in argon-methane and argon-acetylene mixtures under atmospheric pressure conditions. Chem Kinetics. https://doi.org/10.5772/36779

40. Zhang H, Wang W, Li X et al (2018) Plasma activation of methane for hydrogen production in a N2 rotating gliding arc warm plasma: a chemical kinetics study. Chem Eng J 345:67-78. https://doi. org/10.1016/j.cej.2018.03.123

41. Fridman A (2008) Electric discharges in plasma chemistry. In: Plasma chemistry, Cambridge University Press, Cambridge, pp 157-258. https://doi.org/10.1017/cbo9780511546075.006

42. Wang W, Mei D, Tu X, Bogaerts A (2017) Gliding arc plasma for $\mathrm{CO}_{2}$ conversion: better insights by a combined experimental and modelling approach. Chem Eng J 330:11-25. https://doi. org/10.1016/j.cej.2017.07.133

43. Sun SR, Kolev S, Wang HX, Bogaerts A (2017) Investigations of discharge and post-discharge in a gliding arc: a 3D computational study. Plasma Sour Sci Technol 26:55017. https://doi. org/10.1088/1361-6595/aa670a

44. Sun SR, Kolev S, Wang HX, Bogaerts A (2016) Coupled gas flow-plasma model for a gliding arc: investigations of the back-breakdown phenomenon and its effect on the gliding arc characteristics. Plasma Sour Sci Technol 26:015003. https://doi.org/10.1088/0963-0252/26/1/015003

45. Schuepfer DB, Badaczewski F, Guerra-Castro JM et al (2020) Assessing the structural properties of graphitic and non-graphitic carbons by Raman spectroscopy. Carbon N Y 161:359-372. https://doi. org/10.1016/j.carbon.2019.12.094

46. Kumar A, Ann Lin P, Xue A et al (2013) Formation of nanodiamonds at near-ambient conditions via microplasma dissociation of ethanol vapour. Nat Commun 4:1-8. https://doi.org/10.1038/ ncomms 3618 
47. Su CH, Chang $\mathrm{CY}$ (2008) Effect of $\mathrm{CH} / \mathrm{C} 2$ species density on surface morphology of diamond film grown by microwave plasma jet chemical vapor deposition. Mater Trans 49:1380-1384. https://doi. org/10.2320/matertrans.MRA2007324

48. Crintea DL, Czarnetzki U, Iordanova S et al (2009) Plasma diagnostics by optical emission spectroscopy on argon and comparison with Thomson scattering. J Phys D Appl Phys 42:45208. https:// doi.org/10.1088/0022-3727/42/4/045208

49. Kohno H, Berezin AA, Chang JS (1998) Destruction of volatile organic compounds used in a semiconductor industry by a capillary tube discharge reactor. IEEE Trans Ind Appl 34:953-966. https:// doi.org/10.1109/28.720435

50. Liu SY, Mei DH, Nahil MA et al (2017) Hybrid plasma-catalytic steam reforming of toluene as a biomass tar model compound over $\mathrm{Ni} / \mathrm{Al}_{2} \mathrm{O}_{3}$ catalysts. Fuel Process Technol 166:269-275. https:// doi.org/10.1016/j.fuproc.2017.06.001

51. Cataldo F, García-Hernández DA, Manchado A (2019) Toluene pyrolysis in an electric ARC: products analysis. Fuller Nanotube Carbon Nanostruct 27:469-477. https://doi.org/10.1080/15363 83X.2019.1576639

52. Matsugi A, Miyoshi A (2013) Modeling of two- and three-ring aromatics formation in the pyrolysis of toluene. Proc Combust Inst 34:269-277. https://doi.org/10.1016/j.proci.2012.06.032

53. Benndorf C (1994) Mass and optical emission spectoscopy of plasmas for diamond-synthesis. Pure Appl Chem 66:1195-1206. https://doi.org/10.1351/pac199466061195

54. Rabeau JR, John P, Wilson JIB, Fan Y (2004) The role of $\mathrm{C}_{2}$ in nanocrystalline diamond growth. J Appl Phys 96:6724-6732. https://doi.org/10.1063/1.1810637

55. Cai M, Thorpe D, Adamson DH, Schniepp HC (2012) Methods of graphite exfoliation. J Mater Chem 22:24992-25002. https://doi.org/10.1039/C2JM34517J

56. Lim SH, Luo Z, Shen ZX, Lin J (2010) Plasma-assisted synthesis of carbon nanotubes. Nanoscale Res Lett 5:1377-1386. https://doi.org/10.1007/s11671-010-9710-2

Publisher's Note Springer Nature remains neutral with regard to jurisdictional claims in published maps and institutional affiliations. 